\title{
The emergence of carbapenem resistant Klebsiella pneumoniae in Malaysia: correlation between microbiological trends with host characteristics and clinical factors
}

Ye-Mun Low', Polly Soo-Xi Yap', Kartini Abdul Jabar', Sasheela Ponnampalavanar², Rina Karunakaran', Rukumani Velayuthan ${ }^{1}$, Chun-Wie Chong ${ }^{3}$, Sazaly Abu Bakar ${ }^{1,4}$, Mohd Yasim Md Yusof ${ }^{1}$ and Cindy Shuan-Ju Teh ${ }^{1 *}$

\begin{abstract}
Background: Carbapenem resistant Enterobacteriaceae is a growing concern worldwide including Malaysia. The emergence of this pathogen is worrying because carbapenem is one of the 'last-line' antibiotics. The main objective of this study was to determine the prevalence of genetic mechanisms and clinical risk factors of carbapenem resistant Klebsiella pneumoniae (K. pneumoniae) in Malaysia.

Methods: In this study, seventeen carbapenem resistant $K$. pneumoniae strains isolated from a tertiary teaching hospital in 2013 were studied. Minimal inhibitory concentration (MIC) of the bacterial strains was determined and genes associated with carbapenemases and extended-spectrum-beta-lactamases (ESBLs) were sequenced and compared with the closest representatives published in public domains. All strains were also sub-typed using pulsed-field gel electrophoresis (PFGE) and multilocus sequence typing (MLST). Statistical analyses were performed to determine the correlation between risk factors for acquiring carbapenem resistant $K$. pneumoniae and in-hospital mortality.

Results: The predominant carbapenemase was bla $a_{\mathrm{OXA}-48}$, detected in 12 strains (70.59\%). Other carbapenemases detected in this study were bla $a_{\mathrm{KPC}-2}, b / a_{\mathrm{IMP}-8,}, b / a_{\mathrm{NMC}-\mathrm{A}}$ and $b a_{\mathrm{NDM}-1}$. Nine different pulsotypes were identified and nine strains which were affiliated with ST101, the predominant sequence type had similar PFGE patterns (similarity index of 85\%). Based on univariate statistical analysis, resistance to imipenem and usage of mechanical ventilation showed a statistically significant effect separately to in-hospital mortality.

Conclusion: The diverse genetic mechanisms harbored by these carbapenem resistant $K$. pneumoniae facilitates its spread and complicates its detection. Thus, correlation between microbiological trends with host characteristics and clinical factors will provide a better insight of rational treatment strategies and pathogen control.
\end{abstract}

Keywords: Carbapenem resistant K. pneumoniae, OXA-48, KPC-2, ST101, Enterobacteriaceae

\footnotetext{
* Correspondence: cindysjteh@um.edu.my

${ }^{1}$ Department of Medical Microbiology, University of Malaya, 50603 Kuala

Lumpur, Malaysia

Full list of author information is available at the end of the article
} 


\section{Background}

Klebsiella pneumoniae (K. pneumoniae) is an important pathogen responsible for many healthcare associated infections. This Gram-negative bacterium affiliated with the Enterobacteriaceae family is the fourth and fifth most common cause of pneumonia and bacteremia respectively, among intensive care units (ICU), newborn units and in immunocompromised patients [1, 2]. In hospital environments, Klebsiella species survive and multiply in wet environmental sites and colonize the human bowel, bladder, upper respiratory tract and skin [3].

During the 1990s, extended-spectrum beta-lactamases (ESBLs) producing Klebsiella species that are able to hydrolyze broad and extended-spectrum cephalosporins, monobactams and penicillins were reported [4]. Thus, carbapenems, one of the 'last resort antibiotics' were often used to treat serious infections caused by ESBL carrying pathogens.

K. pneumoniae was first reported to harbor Klebsiella pneumoniae carbapenemase (KPC), one of the epidemiologically important carbapenemases first detected in North Carolina, USA in 1996 [5]. It was later identified in outbreaks in USA and was soon detected in many European countries and South America [6]. Initially, it was thought that carbapenemases were attributed to chromosomally encoded beta-lactamases and can only be transferred through clonal spread. However, plasmid encoded $b l a_{\mathrm{IMP}-1}$ and $b l a_{\mathrm{KPC}-1}$ reported in the 1990s [7] confirmed the presence of these resistance genes in mobile genetic elements which implicates potential for resistance transmission through horizontal gene transfer.

The first report of carbapenem resistant K. pneumoniae in Malaysia was an imipenem resistant strain isolated from blood culture of a 42-year old woman in 2004 [8]. To date, carbapenemases harbored by $K$. pneumoniae isolated in Malaysia identified using Pubmed search were NDM-1 [9, 10], OXA-232 [9] and IMP-4 [11].

In this study, we investigated the genotypic characteristics of carbapenem resistant $K$. pneumoniae isolated from patients in a tertiary teaching hospital in Malaysia. Their association with Tn4401 and the loss of porin as well as their subtypes were identified. Further risk factors associated with in-hospital mortality rate were also evaluated.

\section{Methods}

\section{Bacterial isolates}

A total of seventeen Klebsiella pneumoniae strains isolated within an eight-month period in 2013 since the first report of carbapenem resistant Enterobacteriaceae in this tertiary teaching hospital were revived from stock cultures. Antimicrobial susceptibility testing (AST) was conducted and carbapenemase production of the strains was detected by the Modified Hodge Test (MHT) (K.

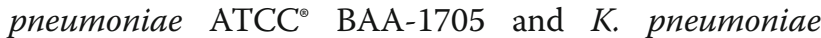
ATCC $^{\oplus}$ BAA-1706 as MHT positive and negative reference strain respectively). Clinical records of the patients from whom strains were isolated were retrieved from the hospital database and ethics approval (MEC:1059.15) was obtained from University of Malaya Medical Centre (UMMC) Ethics Committee prior to the start of this study.

Determination of minimal inhibitory concentration (MIC) These seventeen strains which had been previously detected as resistant to imipenem and/or meropenem based on Clinical and Laboratory Standards Institute (CLSI) guidelines [12] by the hospital's diagnostic microbiology lab were subjected to E-test (bioMérieux, USA) using E. coli ATCC 25922 as the quality control strain for susceptibility testing. The MIC values $(\mu \mathrm{g} / \mathrm{ml})$ for tigecycline, tetracycline, cefoxitin, cefotaxime, ceftazidime, ceftriaxone, cefepime, imipenem, meropenem, ertapenem, gentamicin, tobramycin, amikacin, aztreonam, ciprofloxacin, levofloxacin and colistin were determined. The results were interpreted using CLSI guidelines [12] while susceptibility to colistin and tigecycline were interpreted according to European Committee on Antimicrobial Susceptibility Testing (EUCAST) breakpoints [13]. In brief, imipenem and meropenem resistance were defined as $\mathrm{MIC} \geq 4 \mu \mathrm{g} / \mathrm{ml}$ while ertapenem resistance was defined as $\mathrm{MIC} \geq 2 \mu \mathrm{g} /$ $\mathrm{ml}$.

\section{Pulsed-field gel electrophoresis (PFGE)}

The clonal relatedness of these seventeen strains was determined using PFGE. Briefly, plugs containing whole genomic DNA of $K$. pneumoniae strains were digested with XbaI. The DNA fragments were separated in a PFGE CHEF-DR III system (Bio-Rad, UK). PFGE conditions of $\mathrm{XbaI}$ macrorestriction analysis were $6 \mathrm{Vcm}^{-1}$ for 20 hours, with pulse times ranging from $5 \mathrm{~s}$ to $30 \mathrm{~s}$ at a temperature of $14{ }^{\circ} \mathrm{C}$ and at an angle of $120^{\circ}$. The banding patterns were analyzed using BioNumerics software and similarity $>85 \%$ upon dendrogram analysis was considered to represent the same PFGE pattern groups.

\section{Multilocus sequence typing (MLST)}

Seven housekeeping genes of $K$. pneumoniae namely, gapA, infB, mdh, pgi, phoE, rpoB and tonB were sequenced and analyzed using Institut Pasteur MLST and whole genome MLST database for $K$. pneumoniae, http://bigsdb.web.pasteur.fr/klebsiella/klebsiella.html.

Each locus was assigned an allele number and the sequence type (ST) of each strain was determined based on the allelic profile generated using the allele numbers of the seven loci. 
Detection of carbapenemases, AmpC beta-lactamases, extended-spectrum beta-lactamases (ESBL) and outer membrane porin genes

Carbapenemase genes such as KPC [14], OXA-48 [15], IMP, VIM [16], NDM [6], NMC, IMI, SIM, SPM [7], GIM [17], AmpC beta-lactamases (CMY, DHA, ACC, FOX) [18] as well as other ESBL associated genes such as TEM, SHV [18], OXA-1 [19], OXA-9 [15], CTXM-1, CTXM-2 [20] were amplified via PCR. The amplified products were sequenced and gene types were compared to the nearest gene homology using a BLAST search. The presence of porin associated genes namely ompK35, ompK36 and ompK37 [21] were also determined by PCR.

\section{Determination of genetic elements of Tn4401}

Genetic elements of Tn4401, a $10 \mathrm{~kb}$ Tn3 based transposon commonly found to harbor $b l a_{\mathrm{KPC}}$ was determined as previously described [14,22]. The unconserved region located between ISKpn 7 and $b l a_{\mathrm{KPC}}$ gene was also amplified to determine the isoforms of $\operatorname{Tn} 4401$.

\section{Statistical analyses}

Risk factors associated with in-hospital mortality were compared statistically depending on the level of measurement. Specifically nominal parameters (eg. mechanical ventilation, resistance to antibiotics, etc) were compared using chi-square or Fishers' exact test as appropriate while continuous variables (age and length of hospitalization) were analyzed using either student $t$ test or Mann Whitney $\mathrm{U}$ test depending on data normality. $P$ values less than 0.05 were deemed as statistically significant. Multiple logistic regression was not included in this study due to the small sample size. Continuous variables were summarized as mean \pm standard deviation or median (inter quartile range) for both normal and nonnormal distribution respectively.

\section{Results}

\section{Overview of carbapenem resistant Klebsiella pneumoniae} cases

The first case of carbapenem resistant $K$. pneumoniae in this study was detected from blood culture of a 57-yearold male patient in April 2013 in this 1,000 bed tertiary teaching hospital in Kuala Lumpur, Malaysia. Since then, no new cases were reported until another carbapenem resistant $K$. pneumoniae isolation from peritoneal drainage of a 67-year-old male patient in August 2013. In the following weeks, an average of one new carbapenem resistant case was detected every 2 weeks and as of 19 December 2013, a total of seventeen strains which were resistant to imipenem and/or meropenem were identified from blood $(\mathrm{n}=4)$, urine $(\mathrm{n}=4)$, swabs (stoma, perirectal, foot) $(\mathrm{n}=3)$, drainage fluids (percutaneous transphetic biliary drainage (PTBD), peritoneal) $(\mathrm{n}=2)$, tracheal secretion $(\mathrm{n}=1)$, tracheal aspirate $(\mathrm{n}=1)$, sputum $(\mathrm{n}=1)$ and tissue $(\mathrm{n}=1))$. The time-line of events during in-patient admission period including the wards stayed and carbapenem resistant $K$. pneumoniae strains isolation from the sixteen patients from March 2013 to April 2014 was illustrated in Fig. 1. Four of the patients stayed in surgical wards, four in medical wards, two in orthopedic wards and six others moved from different wards. A total of four patients stayed in ICU during their admission period.

These strains were the first carbapenem resistant $K$. pneumoniae isolate from each patient with the exception of two strains which were isolated from a 60-year-old male patient. The first strain isolated from this patient was in October 2013 from tracheal aspirate. Subsequently, we did not identify carbapenem resistant $K$. pneumoniae from respiratory samples with the Vitek2 automated susceptibility testing system in 2013 while urine samples had no growth from October until November 2013. However, carbapenem resistant $K$. pneumoniae was detected in this patient's urine samples in December 2013.

This study was conducted in a multiracial community in Malaysia which comprises of three major races namely Malays, Chinese and Indians. There were nine male patients and seven female patients. The mean age of the patients was 66.13 years where the youngest patient was 48-years-old while the eldest was 85-years-old (Table 1). The average length of hospitalization prior to strain isolation was 65.18 days. Two carbapenem resistant $K$. pneumoniae strains (K/1309-38 and K/1311-26) were isolated from urine and blood respectively from two different patients within 48 hours of admission and one of the patients (K/1309-38) had came into contact with healthcare facilities in the past 30 days for endoscopic procedures. All patients in this study had comorbidities such as diabetes mellitus, hypertension, chronic kidney disease and solid organ tumors. Diabetes mellitus and hypertension were the predominant noncommunicable diseases identified in these patients.

All 16 patients had been administered antibiotics over a period of 90 days prior to carbapenem resistant $K$. pneumoniae strain isolation. Cephalosporins and betalactam/beta-lactamase inhibitor combinations were the two most common classes of antibiotics being administered to them. These patients had been treated empirically with antibiotics such as beta-lactam/beta-lactamase inhibitors, carbapenems, cephalosporins, ciprofloxacin, vancomycin and colistin prior to carbapenem resistant K. pneumoniae identification (Table 1).

Eight patients $(47.06 \%)$ in this study were infected with carbapenem resistant $K$. pneumoniae while others were considered to be colonized. Of the eight infected 


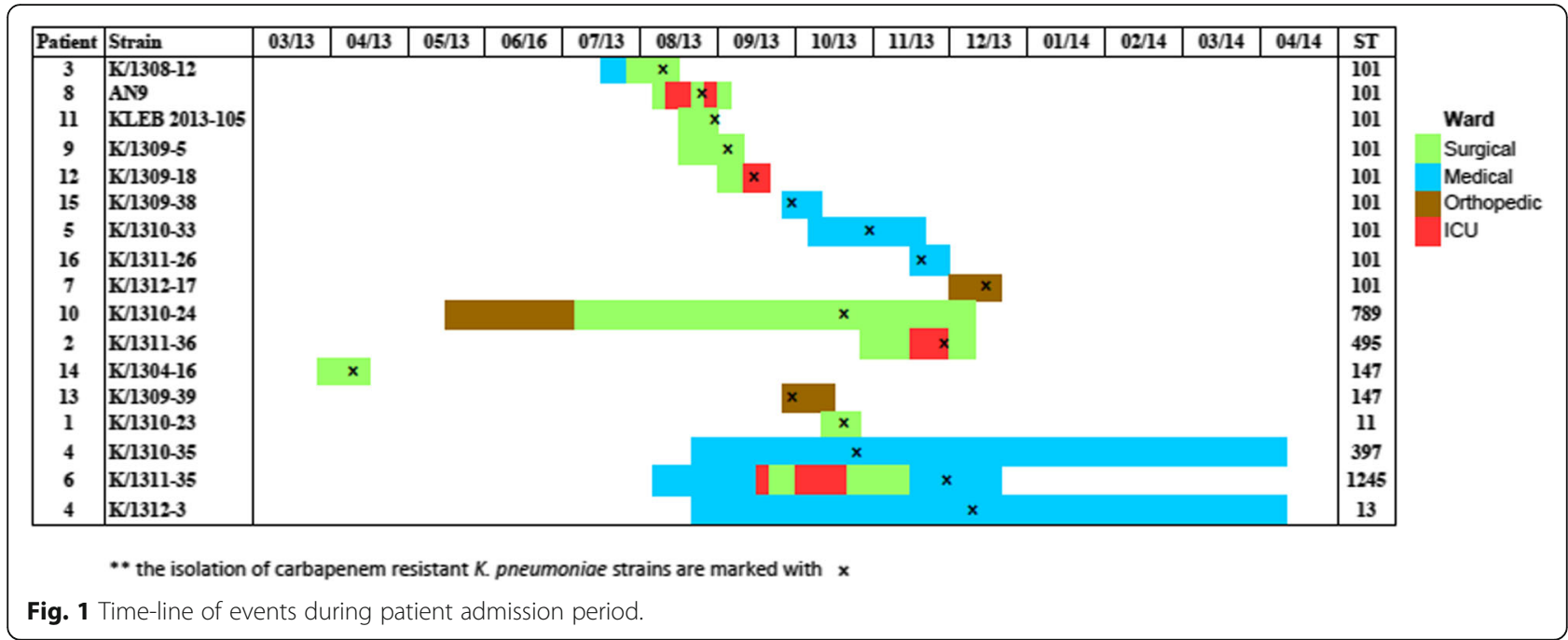

patients, one of them had changed their antimicrobial regimen to colistin while five others were given carbapenem and colistin combination. One patient (12.5\%) died before changing therapy and another continued with colistin therapy.

Risk factors such as surgical procedures undergone, usage of mechanical ventilation and the usage of catheter were also taken into consideration. However, based on univariate analyses, only the usage of mechanical ventilation $(P=0.043)$ shows significant effect to inhospital mortality rate (Table 2 ).

\section{Determination of minimal inhibitory concentration (MIC)} The antibiotic profiles were tabulated in Table 3. Briefly, all strains were resistant to tetracycline (two strains were intermediate) but only one strain was resistant to tigecycline. Meanwhile, all strains were sensitive to colistin. Eight strains $(47.06 \%)$ were resistant to all cephalosporins and all strains showed resistance to at least one carbapenem ( $\mathrm{MIC}=4->32 \mu \mathrm{g} / \mathrm{ml})$ in this study. Resistance to imipenem was significantly associated with in-hospital mortality $(P=0.043)$ (Table 2$)$. It was also noted that two strains (K/1311-35 and $\mathrm{K} / 1304-16)$ were resistant to imipenem $(\mathrm{MIC}=4-6 \mu \mathrm{g} / \mathrm{ml})$ but were sensitive to meropenem and ertapenem while one strain (K/1312-3) was sensitive to imipenem but resistant to meropenem and ertapenem (MIC $=6-16 \mu \mathrm{g} / \mathrm{ml})$. Furthermore, three strains $(17.65 \%)$ were resistant to all aminoglycosides $(\mathrm{MIC}=24->256 \mu \mathrm{g} / \mathrm{ml}$ for gentamicin and tobramycin; $\mathrm{MIC}=64->256 \mu \mathrm{g} / \mathrm{ml}$ for amikacin) while thirteen strains $(76.47 \%)$ were resistant to all fluoroquinolones $(\mathrm{MIC}=8->32 \mu \mathrm{g} / \mathrm{ml})$.

\section{Molecular typing via PFGE \& MLST}

Based on the PFGE patterns obtained, the seventeen strains formed nine different pulsotypes while MLST analysis showed eight STs (Fig. 2). Nine strains affiliated with the predominant sequence type, ST101 demonstrated similar PFGE patterns (Dice index $>85 \%$ homology) suggesting close intra ST-type genomic similarity. Five of the ST101 strains were isolated within a week apart from one another in August until September 2013 from patients who had stayed in surgical wards. Two weeks later, this sequence type was isolated from one patient in the medical ward and in the following months from two patients in medical wards and one patient from the orthopedic ward. It was also noted that three other sequence types, ST789, ST11 and ST495 were isolated from patients who had stayed in surgical wards two months after the first ST101 isolation and one of the patients had stayed in the surgical ward in August 2013. All ST101 strains in this study were highly resistant to meropenem (MIC $>32 \mu \mathrm{g} / \mathrm{ml}$ ) and ertapenem $(\mathrm{MIC}=24->32 \mu \mathrm{g} / \mathrm{ml})$. High MIC was also observed for imipenem (MIC $>32 \mu \mathrm{g} / \mathrm{ml}$ ) with the exception of three strains which had lower MICs ranging from $2 \mu \mathrm{g} /$ $\mathrm{ml}$ (intermediate) to $4 \mu \mathrm{g} / \mathrm{ml}$ (resistant).

Similarly, two strains (K/1304-16 and K/1309-39) (Dice index $=84.2 \%$ homology) from the same subcluster were categorized into the same sequence type, ST147. However, two other strains, K/1310-35 and K/ 1312-3 which were isolated two months apart from a 60-year-old male patient exhibited distinct PFGE pattern and sequence type (ST397 and ST13 respectively); indicating low relatedness.

\section{Detection of carbapenemases, AmpC beta lactamases, extended spectrum beta lactamases (ESBL) and porin protein genes}

AmpC (bla $\left.a_{\mathrm{FOX}-7}\right)$ and ESBLs (bla $a_{\mathrm{SHV}}, b l a_{\mathrm{TEM}}, b l a_{\mathrm{CTXM}-2}$ $\left.b l a_{\text {СТХМ-15 }}, b l a_{\text {OXA-1 }}, b l a_{\text {OXA-9 }}\right)$ were present in all 17 strains while carbapenemases $\left(b l a_{\mathrm{KPC}-2}, \quad b l a_{\mathrm{OXA}-48}\right.$, 


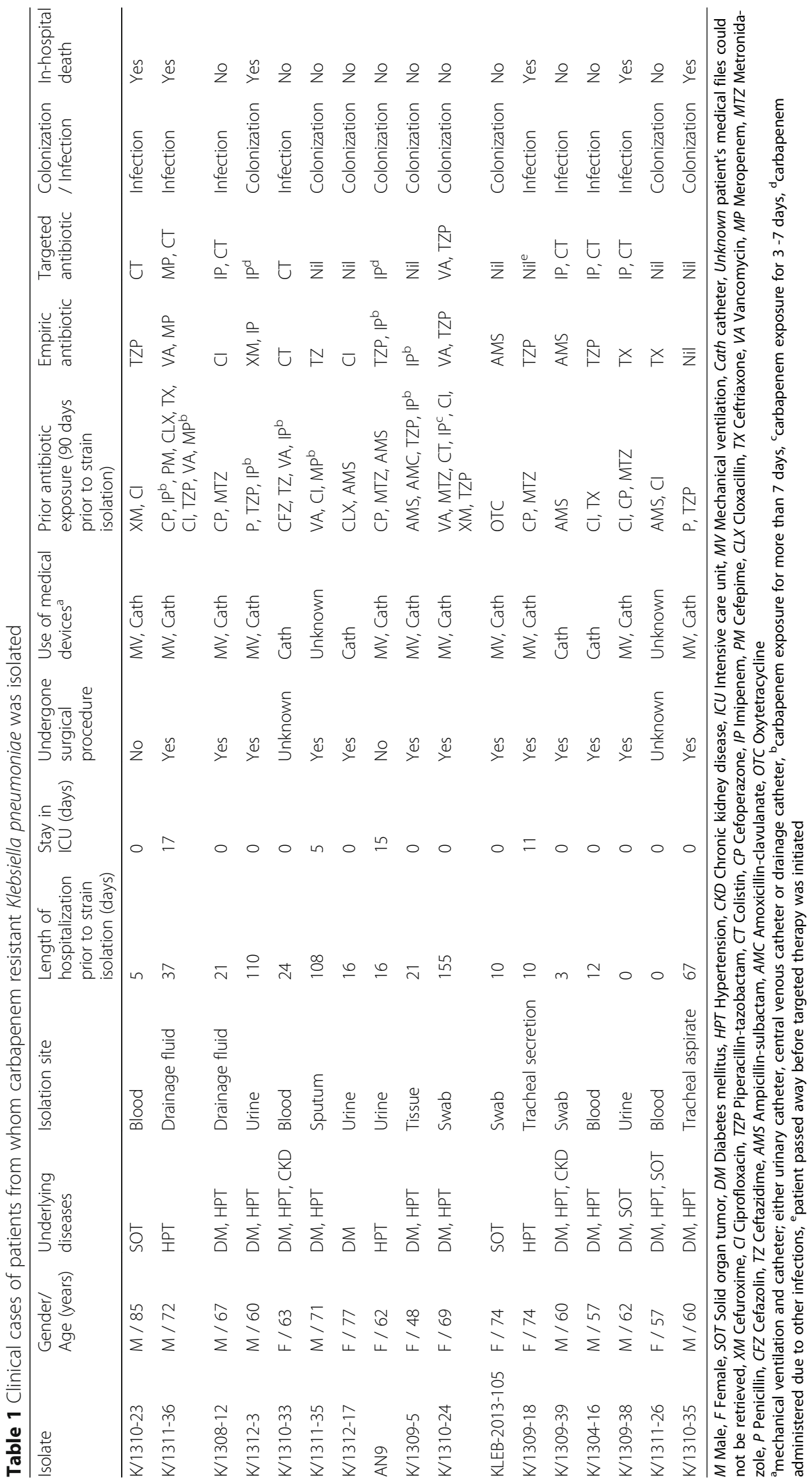


Table 2 Characteristics of carbapenem resistant Klebsiella pneumoniae associated with in-hospital mortality.

\begin{tabular}{|c|c|c|c|}
\hline Characteristics & Survivors $(n=11)$ & Non-survivors $(n=6)$ & $P$ \\
\hline Age (years) & $64.09 \pm 2.57$ & $68.83 \pm 4.09$ & $0.351^{b}$ \\
\hline \multicolumn{4}{|l|}{ Ethnicity } \\
\hline Malay & 2 & 2 & $0.317^{c}$ \\
\hline Chinese & 6 & 3 & $0.317^{c}$ \\
\hline Indian & 3 & 1 & $1.000^{c}$ \\
\hline \multicolumn{4}{|l|}{ Gender } \\
\hline Male & 4 & 5 & $0.111^{c}$ \\
\hline Female & 7 & 1 & $0.034^{c}$ \\
\hline \multicolumn{4}{|l|}{ Underlying diseases } \\
\hline Hypertension & $9(82 \%)$ & $4(67 \%)$ & 0.584 \\
\hline Diabetes mellitus & $9(82 \%)$ & $3(50 \%)$ & 0.280 \\
\hline Solid organ tumor & $2(18 \%)$ & $2(33 \%)$ & 0.584 \\
\hline Chronic kidney disease & $2(18 \%)$ & $0(0 \%)$ & 0.515 \\
\hline \multicolumn{4}{|l|}{ Site of isolation } \\
\hline Blood & $3(27.3 \%)$ & $1(16.7 \%)$ & 0.515 \\
\hline Swabs & $3(27.3 \%)$ & $0(0 \%)$ & 0.515 \\
\hline Urine & $2(18.2 \%)$ & $2(33.3 \%)$ & 0.58 \\
\hline Drainage fluids & $1(9.1 \%)$ & $1(16.7 \%)$ & 1.000 \\
\hline Sputum & $1(9.1 \%)$ & $0(0 \%)$ & 1.000 \\
\hline Tissue & $1(9.1 \%)$ & $0(0 \%)$ & 1.000 \\
\hline Tracheal aspirate & $0(0 \%)$ & $1(16.7 \%)$ & 0.353 \\
\hline Tracheal secretion & $0(0 \%)$ & $1(16.7 \%)$ & 0.353 \\
\hline Length of hospitalization (days) & $35.09 \pm 14.88$ & $38.17 \pm 17.65$ & $1.000^{\mathrm{d}}$ \\
\hline Stay in ICU & $2(18 \%)$ & $2(33 \%)$ & 0.584 \\
\hline Undergone surgical procedure & $8(73 \%)$ & $5(83 \%)$ & 1.000 \\
\hline Used ventilation devices & $5(45 \%)$ & $6(100 \%)$ & 0.043 \\
\hline Used catheter & $9(82 \%)$ & $6(100 \%)$ & 0.515 \\
\hline \multicolumn{4}{|l|}{$\begin{array}{l}\text { Antibiotic prescribed } 90 \\
\text { days prior to strain isolation }\end{array}$} \\
\hline Cephalosporins & $6(55 \%)$ & $4(67 \%)$ & 1.000 \\
\hline $\begin{array}{l}\text { Penicillins \& beta-lactam/beta-lactamase } \\
\text { inhibitors }\end{array}$ & $6(55 \%)$ & $3(50 \%)$ & 1.000 \\
\hline Carbapenems & $4(36 \%)$ & $2(33 \%)$ & 1.000 \\
\hline Colistin & $1(9 \%)$ & 0 & 1.000 \\
\hline $\begin{array}{l}\text { Others (ciprofloxacin, vancomycin, } \\
\text { metronidazole \& oxytetracycline) }\end{array}$ & $8(73 \%)$ & $4(67 \%)$ & 1.000 \\
\hline \multicolumn{4}{|l|}{ Empiric treatment } \\
\hline Beta-lactam/beta-lactamase inhibitors & $5(46 \%)$ & $2(33 \%)$ & 1.000 \\
\hline Cephalosporins & $2(18 \%)$ & $2(33 \%)$ & 0.584 \\
\hline Carbapenems & $2(18 \%)$ & $2(33 \%)$ & 0.584 \\
\hline Ciprofloxacin & $2(18 \%)$ & 0 & 0.515 \\
\hline Vancomycin & $1(9 \%)$ & $1(17 \%)$ & 1.000 \\
\hline Colistin & $1(9 \%)$ & 0 & 1.000 \\
\hline \multicolumn{4}{|l|}{ Targeted therapy } \\
\hline Carbapenem + Colistin & $3(27 \%)$ & $2(33 \%)$ & 1.000 \\
\hline
\end{tabular}


Table 2 Characteristics of carbapenem resistant Klebsiella pneumoniae associated with in-hospital mortality. (Continued)

\begin{tabular}{|c|c|c|c|}
\hline Colistin & $1(9 \%)$ & $1(17 \%)$ & 1.000 \\
\hline Carbapenem (Meropenem / Imipenem) & $1(9 \%)$ & $1(17 \%)$ & 1.000 \\
\hline Vancomycin \& Piperacillin-tazobactam & $1(9 \%)$ & 0 & 1.000 \\
\hline $\mathrm{Nil}^{\mathrm{a}}$ & $5(46 \%)$ & $2(33 \%)$ & 1.000 \\
\hline \multicolumn{4}{|l|}{ Colonization / Infection } \\
\hline Colonization & $7(63 \%)$ & $2(33 \%)$ & 0.162 \\
\hline Infection & $4(36 \%)$ & $4(67 \%)$ & 0.162 \\
\hline \multicolumn{4}{|l|}{ Resistance to antibiotics (MIC) } \\
\hline Imipenem & $10(91 \%)$ & $2(33 \%)$ & $0.04^{c}$ \\
\hline Meropenem & $9(82 \%)$ & $6(100 \%)$ & 0.515 \\
\hline Ertapenem & $9(82 \%)$ & $5(83 \%)$ & $0.232^{\circ}$ \\
\hline \multicolumn{4}{|l|}{ Carbapenemases } \\
\hline OXA-48 & $8(73 \%)$ & $4(67 \%)$ & 1.000 \\
\hline $\mathrm{KPC}-2$ & $5(45 \%)$ & $3(50 \%)$ & 1.000 \\
\hline IMP-8 & $2(18 \%)$ & $0(0 \%)$ & 0.515 \\
\hline NMC-A & $0(0 \%)$ & $2(33 \%)$ & 0.110 \\
\hline NDM-1 & $1(9 \%)$ & $0(0 \%)$ & 1.000 \\
\hline \multicolumn{4}{|l|}{ AmpC beta-lactamases } \\
\hline FOX-7 & $11(100 \%)$ & $6(100 \%)$ & NA \\
\hline \multicolumn{4}{|l|}{ ESBL } \\
\hline CTXM-2 & $11(100 \%)$ & $6(100 \%)$ & NA \\
\hline SHV & $11(100 \%)$ & $6(100 \%)$ & NA \\
\hline OXA-1 & 7 (64\%) & $2(33 \%)$ & 0.335 \\
\hline CTXM-15 & $6(55 \%)$ & $4(67 \%)$ & 1.000 \\
\hline TEM & $6(55 \%)$ & $3(50 \%)$ & 1.000 \\
\hline OXA-9 & $6(55 \%)$ & $1(17 \%)$ & $0.304^{c}$ \\
\hline
\end{tabular}

Values are expressed as $n$ (\%) except where otherwise noted.

atargeted therapy was not administered as strain was colonizer or patient passed away before targeted therapy was initiated

$P$-values were obtained using Fishers' exact test unless noted otherwise. ${ }^{b} P$-values obtained using student $t$ test, ${ }^{c} P$-values obtained using chi-square, ${ }^{d} P$-values obtained using Mann Whitney $\mathrm{U}$ test. The significant $P$ values were highlighted in bold.

$\left.b l a_{\mathrm{IMP}-8}, b l a_{\mathrm{NDM}-1}, b l a_{\mathrm{NMC}-\mathrm{A},}\right)$ were detected in only 16 strains where $b l a_{\text {OXA-48 }}$ was the dominant carbapenemase (Table 4). All strains also exhibited the presence of three outer membrane porins (ompK35, ompK36, ompK37) with the exception of K/1310-24 where ompK36 was absent. This strain, K/1310-24 also showed the highest resistance towards imipenem $(\mathrm{MIC}=6 \mu \mathrm{g}$ / $\mathrm{ml})$, meropenem $(\mathrm{MIC}=>32 \mu \mathrm{g} / \mathrm{ml}$ ) and ertapenem $(\mathrm{MIC}=6 \mu \mathrm{g} / \mathrm{ml})$ among the group of six strains made up of sequence type other than ST101 and ST147.

\section{Characterization results for $\mathrm{Tn} 4401$}

Primer pairs specific for different genetic elements on Tn4401 were used to deduce the structure of it. A schematic representation of a typical Tn4401 structure is shown in Fig. 3a. All strains harboring bla $a_{\mathrm{KPC}-2}$ showed the presence of Tn4401 elements which indicated that $b l a_{\mathrm{KPC}-2}$ gene was carried within Tn4401 transposon (Table 4).

Isoforms of Tn4401 were determined based on the fragment size of primer pair hybridizing ISKpn7 and bla $a_{\mathrm{KPC}}$; upstream of $b l a_{\mathrm{KPC}}$ [22]. All six strains which showed positive amplification were of the same DNA fragment size (703 bp) and they belonged to isoform $b$ where no deletion in the variable region is observed. Among these six strains, one was sensitive, two were intermediate while three exhibited resistance to imipenem $(\mathrm{MIC}=4->32 \mu \mathrm{g} / \mathrm{ml})$ but all strains were resistant to meropenem and ertapenem $(\mathrm{MIC}=6$ - >32 $\mu \mathrm{g} / \mathrm{ml}$ ). Both flanking sequences of Tn4401, inverted repeat left (IRL) and inverted repeat right (IRR) were present in three out of 17 strains (17.65\%) while three others (17.65\%) showed only one flanking sequence. Complete Tn4401 was not detected in this study as some elements were absent in all strains. 


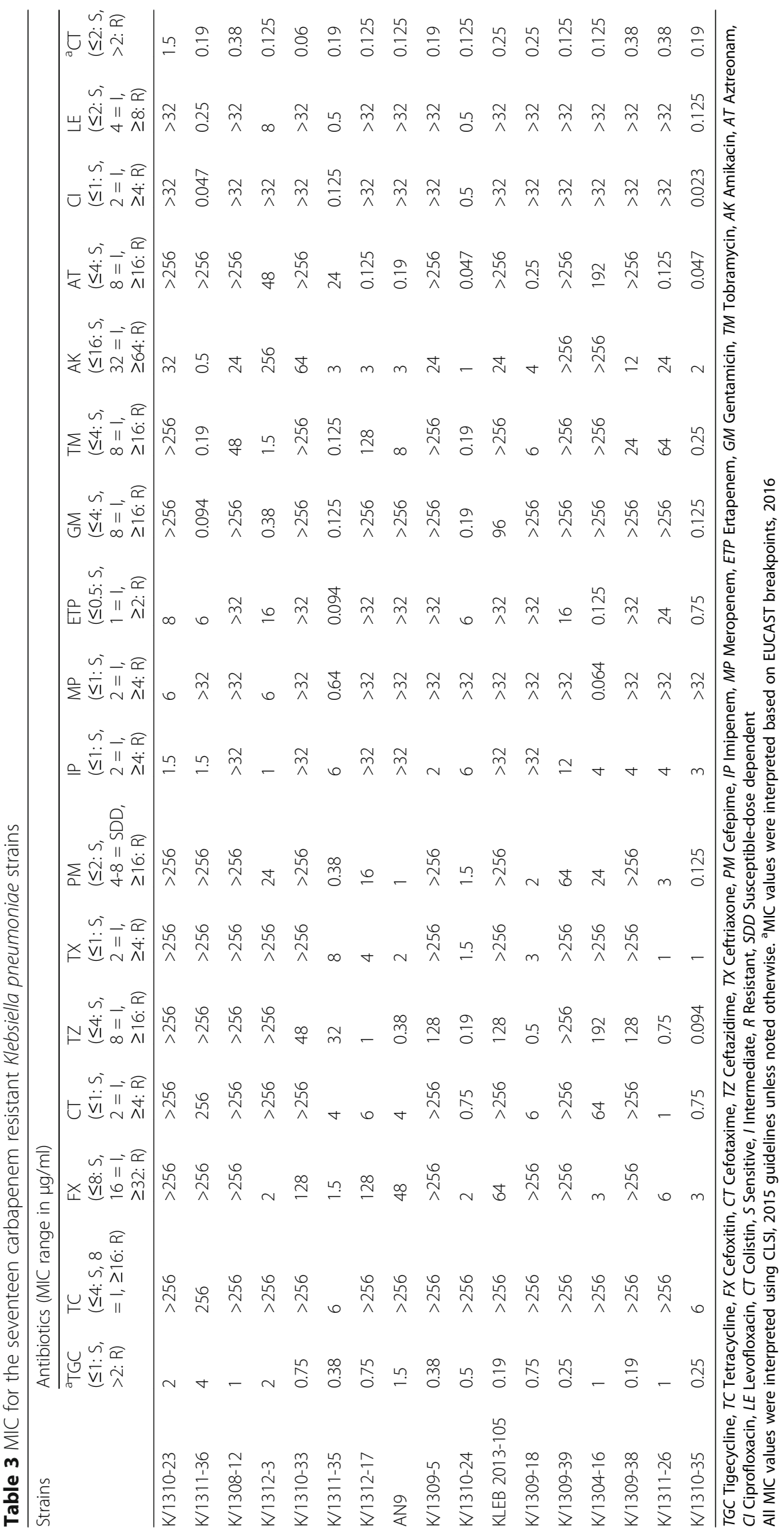




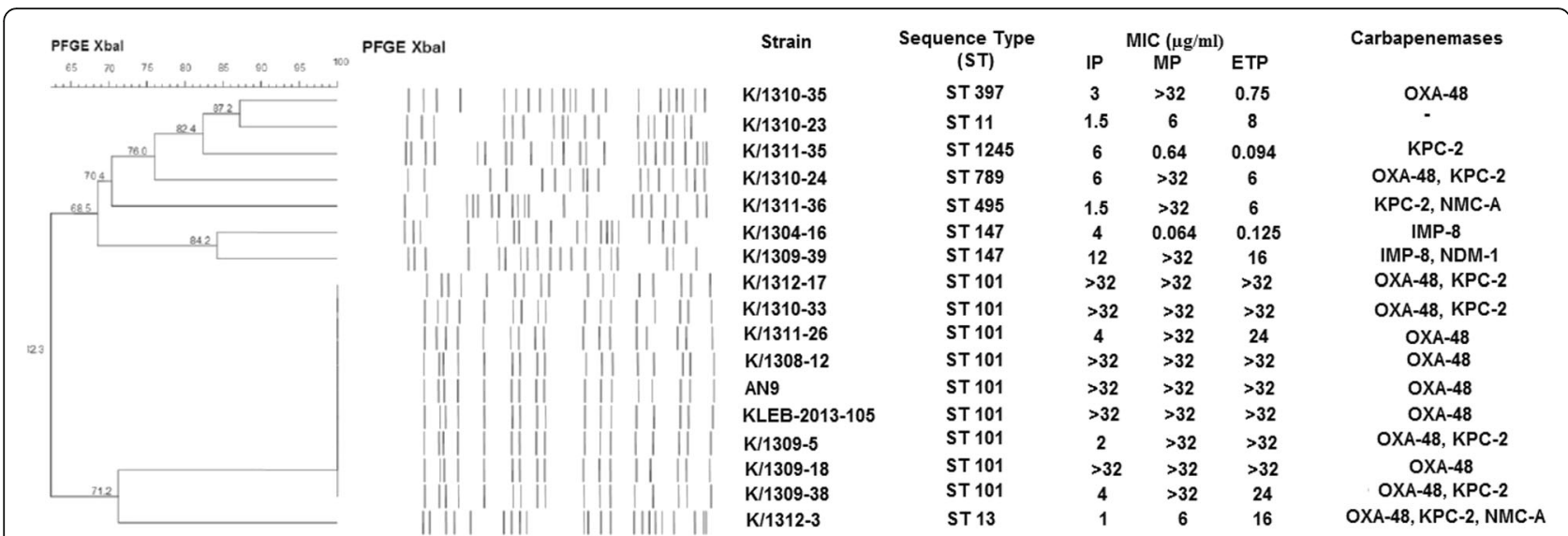

Fig. 2 Dendogram of PFGE banding patterns of carbapenem resistant Klebsiella pneumoniae and their sequence type (ST) determined via MLST together with their antibiotic and genotypic profile. IP: imipenem, MP: meropenem, ETP:ertapenem

Table 4 PCR results of gene specific primers depicting Carbapenemase, AmpC, ESBL, porin protein and Tn4401-like elements in carbapenem resistant Klebsiella pneumoniae strains

\begin{tabular}{|c|c|c|c|c|c|c|c|c|c|c|c|}
\hline \multirow[t]{2}{*}{ Strain } & \multirow{2}{*}{$\begin{array}{l}\text { Sequence } \\
\text { Type (ST) }\end{array}$} & \multirow[t]{2}{*}{ Carbapenemase } & \multirow[t]{2}{*}{ AmpC } & \multirow[t]{2}{*}{ ESBL } & \multirow[t]{2}{*}{ Porin protein } & \multicolumn{6}{|c|}{ Genetic elements surrounding Tn4401 } \\
\hline & & & & & & $\overline{\mathrm{IRL}}$ & tnpA & ISKpn7 & ISKpn6 & $\begin{array}{l}\text { Variable } \\
\text { region }\end{array}$ & IRR \\
\hline K/1310-23 & 11 & - & FOX-7 & SHV-11, CTXM-15, CTXM-2 & $\begin{array}{l}\text { OmpK35, OmpK36, } \\
\text { OmpK37 }\end{array}$ & - & - & - & - & - & - \\
\hline K/1311-36 & 495 & $\mathrm{KPC}-2, \mathrm{NMC}-\mathrm{A}$ & FOX-7 & $\begin{array}{l}\text { TEM-135, SHV-12, CTXM-15, } \\
\text { CTXM-2 }\end{array}$ & $\begin{array}{l}\text { OmpK35, OmpK36, } \\
\text { OmpK37 }\end{array}$ & + & - & + & - & + & + \\
\hline K/1308-12 & 101 & OXA-48 & FOX-7 & $\begin{array}{l}\text { TEM-1, SHV-28, OXA-1, OXA-9, } \\
\text { CTXM-15, CTXM-2 }\end{array}$ & $\begin{array}{l}\text { OmpK35, OmpK36, } \\
\text { OmpK37 }\end{array}$ & - & - & - & - & - & - \\
\hline K/1312-3 & 13 & $\begin{array}{l}\text { OXA- } 48, \text { KPC-2, } \\
\text { NMC-A }\end{array}$ & FOX-7 & $\begin{array}{l}\text { TEM-135, SHV-148, CTXM-15, } \\
\text { CTXM-2 }\end{array}$ & $\begin{array}{l}\text { OmpK35, OmpK36, } \\
\text { OmpK37 }\end{array}$ & - & - & + & - & + & + \\
\hline K/1310-33 & 101 & OXA-48, KPC-2 & FOX-7 & $\begin{array}{l}\text { TEM-1, SHV-28, OXA-1, OXA-9, } \\
\text { CTXM-15, CTXM-2 }\end{array}$ & $\begin{array}{l}\text { OmpK35, OmpK36, } \\
\text { OmpK37 }\end{array}$ & - & - & + & + & + & - \\
\hline K/1311-35 & 1245 & $\mathrm{KPC}-2$ & FOX-7 & SHV-12, CTXM-2 & $\begin{array}{l}\text { OmpK35, OmpK36, } \\
\text { OmpK37 }\end{array}$ & - & + & - & - & - & + \\
\hline K/1312-17 & 101 & OXA-48, KPC-2 & FOX-7 & SHV-28, OXA-1, CTXM-2 & $\begin{array}{l}\text { OmpK35, OmpK36, } \\
\text { OmpK37 }\end{array}$ & - & - & - & + & - & - \\
\hline AN9 & 101 & OXA-48 & FOX-7 & SHV-28, OXA-1, CTXM-2 & $\begin{array}{l}\text { OmpK35, OmpK36, } \\
\text { OmpK37 }\end{array}$ & - & - & - & - & - & - \\
\hline K/1309-5 & 101 & OXA-48, KPC-2 & FOX-7 & $\begin{array}{l}\text { TEM-1, SHV-28, OXA-1, OXA-9, } \\
\text { CTXM-15, CTXM-2 }\end{array}$ & $\begin{array}{l}\text { OmpK35, OmpK36, } \\
\text { OmpK37 }\end{array}$ & - & - & + & + & + & - \\
\hline K/1310-24 & 789 & OXA-48, KPC-2 & FOX-7 & SHV-121, CTXM-2 & OmpK35, OmpK37 & - & - & + & - & + & + \\
\hline $\begin{array}{l}\text { KLEB } \\
\text { 2013-105 }\end{array}$ & 101 & OXA-48 & FOX-7 & $\begin{array}{l}\text { TEM-1, SHV-28, OXA-1, OXA-9, } \\
\text { CTXM-15, CTXM-2 }\end{array}$ & $\begin{array}{l}\text { OmpK35, OmpK36, } \\
\text { OmpK37 }\end{array}$ & - & - & - & - & - & - \\
\hline K/1309-18 & 101 & OXA-48 & FOX-7 & SHV-28, OXA-1, CTXM-2 & $\begin{array}{l}\text { OmpK35, OmpK36, } \\
\text { OmpK37 }\end{array}$ & - & - & - & - & - & - \\
\hline K/1309-39 & 147 & IMP-8, NDM-1 & FOX-7 & $\begin{array}{l}\text { TEM-1, SHV-11, OXA-9, CTXM-15, } \\
\text { CTXM-2 }\end{array}$ & $\begin{array}{l}\text { OmpK35, OmpK36, } \\
\text { OmpK37 }\end{array}$ & - & - & - & - & - & - \\
\hline K/1309-38 & 101 & OXA-48, KPC-2 & FOX-7 & $\begin{array}{l}\text { TEM-1, SHV-28, OXA-1, OXA-9, } \\
\text { CTXM-15, CTXM-2 }\end{array}$ & $\begin{array}{l}\text { OmpK35, OmpK36, } \\
\text { OmpK37 }\end{array}$ & - & - & + & + & + & - \\
\hline K/1311-26 & 101 & OXA-48 & FOX-7 & SHV-28, OXA-1, CTXM-2 & $\begin{array}{l}\text { OmpK35, OmpK36, } \\
\text { OmpK37 }\end{array}$ & - & - & - & - & - & - \\
\hline K/1310-35 & 397 & OXA-48 & FOX-7 & SHV-1, CTXM-2 & $\begin{array}{l}\text { OmpK35, OmpK36, } \\
\text { OmpK37 }\end{array}$ & + & - & - & - & - & + \\
\hline
\end{tabular}




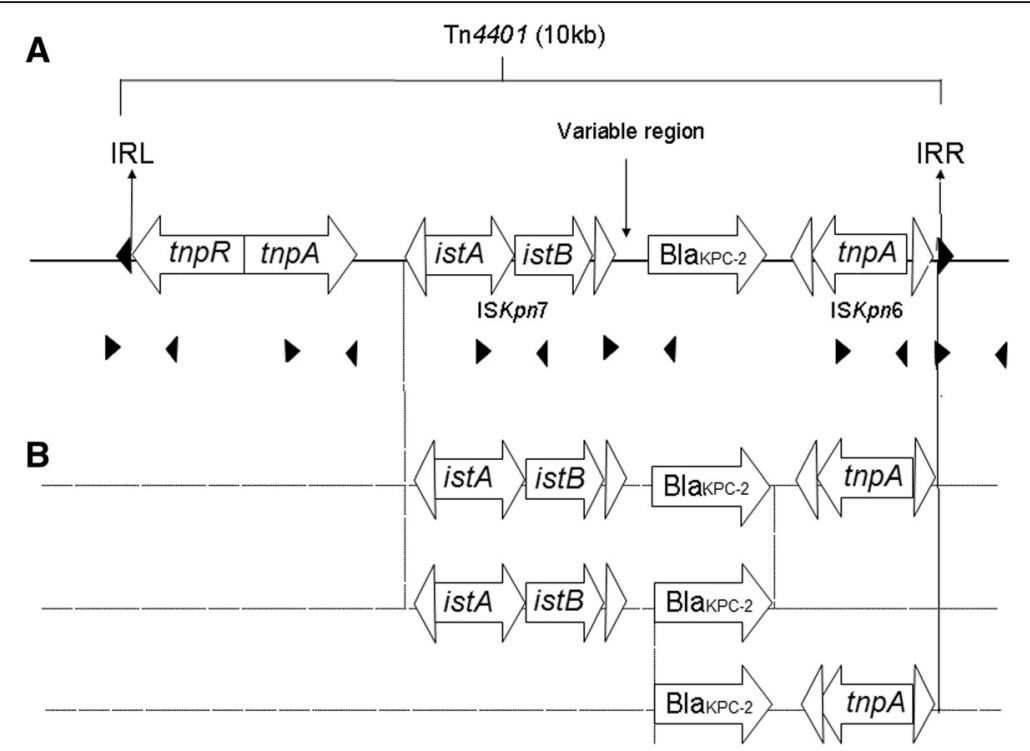

Fig. 3 Shaded triangles represent inverted repeats (IR) sequences. Empty triangles represent IRs of insertion sequences, ISKpn6 and ISKpn7. The location of the variable region is as labeled. (Adapted from [14] and [22]). a: Schematic representation of intact classical Tn4401. b: Examples of truncated Tn4401 detected in this study. ISKpn7, encodes two consecutive open reading frames (ORF); istA which encodes a 341-amino-acid putative transposase while istB encodes a 259-amino-acid transposition helper protein. TnpA encodes a transposase of 1,009 amino acids while thp $R$ is a 1,713 bp resolvase gene

Examples of truncated Tn4401 detected in this study were shown in Fig. 3b.

\section{Discussion}

Among the seventeen carbapenem resistant K. pneumoniae strains investigated, two of them (K/1310-35 and $\mathrm{K} /$ 1312-3) showed distinct pulsotypes, sequence types and resistotypes, indicating non-clonal relationship despite being isolated from the same patient. During an outbreak investigation of ESBL producing $K$. pnemoniae in a neonatal intensive care unit in Germany, Haller and co-workers [23] found two isolates from the same patient taken 138 days apart to be affiliated with separate clusters on phylogenetic tree. This could indicate the presence of diverse pathogen populations within individuals which complicates treatment. These two strains isolated in this study were colonizers (strains isolated from tracheal aspirate and urine) and this patient died after 229 days of hospitalization. Dautzenberg and co-workers [24] have reported that patients colonized with carbapenem resistant Enterobacteriaceae have higher mortality rates as compared to non-colonized patients due to long hospital stay.

The administration of multiple antibiotics has been reported as a risk factor for carbapenem resistance acquisition [25] and all sixteen patients in this study were given at least one antibiotic in the past 90 days prior to carbapenem resistant $K$. pneumoniae isolation. Five patients had been administered with carbapenems for more than seven days and another for three days while the ten other patients were exposed to other beta-lactams (penicillins, beta-lactam/beta-lactamase inhibitors and cephalosporins), ciprofloxacin, vancomycin, metronidazole, oxytetracycline and colistin. This is agreeable with findings as shown by Patel and co-workers [26] that carbapenem resistance is not attributed only to previous exposure to carbapenem but also exposure to other antibiotics.

One strain, K/1310-23 harbored only AmpC (bla $\left.\mathrm{FOX}_{-7}\right)$ and ESBLs (bla $a_{\mathrm{SHV}-11}, b l a_{\mathrm{CTXM-15}}$ and $\left.b l a_{\mathrm{CTXM-2}}\right)$ without the presence of carbapenemases or loss of porin but it was resistant to meropenem $(\mathrm{MIC}=6 \mu \mathrm{g} / \mathrm{ml})$ and ertapenem $(\mathrm{MIC}=8 \mu \mathrm{g} / \mathrm{ml})$. This may be due to reduced porin expression [27] in the strain or this strain may have harbored rare carbapenemases or variants that were not tested for in this study. Only strain, K/1310-24 was associated with loss of porin; ompK 36 and it also harbored carbapenemases $\left(b l a_{\mathrm{OXA}-48}\right.$ and $\left.b l a_{\mathrm{KPC}-2}\right)$. This strain also exhibited the highest resistance towards carbapenems in the group of strains other than ST101 and ST147 which supports the findings that loss of porin together with the presence of $b l a_{\mathrm{KPC}-2}$ is associated with elevated carbapenem MIC [28].

It was also observed that three strains exhibited varying susceptibility patterns to carbapenems tested in this study. K/1311-35 and K/1304-16 were resistant to imipenem but sensitive to meropenem and ertapenem while K/1312-3 was sensitive to imipenem but resistant to meropenem and ertapenem. This discrepany in resistance pattern often poses a challenge in carbapenem 
resistant detection especially if either imipenem or meropenem is used as a representative carbapenem in the screening system $[29,30]$. Imipenem resistant, meropenem sensitive Pseudomonas aeruginosa and imipenem sensitive, meropenem resistant $K$. pneumoniae strains have been previously reported [30, 31]. This difference in susceptibility patterns can be attributed to the variation in outer membrane porin structure and the efflux pumps expression. The eight amino acid sequence deletion on loop L7 of $O p r D$, a carbapenem-specific porin in $P$. aeruginosa sufficiently opens the porin channel, allowing optimal penetration of meropenem and increases its activity without affecting the susceptibility of smaller carbapenem molecules such as imipenem [32]. The overexpression of resistance-nodulation-cell division (RND) efflux pump in $P$. aeruginosa has also been reported to cause varying carbapenem MIC levels [33]. Thus, we postulate that there may be similar porin structure and efflux pump variations in $K$. pneumoniae that contribute to this discrepancy in carbapenem resistance.

Overall, PFGE and MLST produced comparable clustering results. The predominant sequence type, ST101 $(n=9)$ shared the same pulsotype. This characteristic had been reported by Kitchel and co-workers [34] where K. pneumoniae strains with $\geq 80 \%$ similarity in PFGE patterns strongly agreed with their MLST results. It was observed that ST101 spread occurred in the surgical ward in August 2013 as five of ST101 strains were isolated from five different patients who had stayed in surgical wards during this one month period. However, ST101 was also isolated from three other patients from medical wards and one patient from orthopedic ward in the following months. We postulate that more complicated transmission routes such as asymptomatic patients who were never detected, via health care personnel or medical devices [35] may have contributed to the spread of ST101 to patients from other wards. ST789, ST11 and ST495 were also isolated from three separate patients in surgical wards in October and November 2013 and one of the patients had came into contact with the ST101 harboring patients as they shared the same ward in August and was colonized. Despite being phylogenetically unrelated to ST101, these three strains harbor similar ESBL and carbapenemase genes indicating horizontal gene transfer may occur since these genes are often found on transposons and plasmids [36, 37].

Our finding of ST101 as a predominant strain is similar to the report of ST101 as a predominant K. pneumoniae clone in an acute general hospital in Italy [38]. ST101 was reported to be responsible for $b l a_{\text {OXA-48 }}$ outbreaks in Spain and Tunisia [36] and harboring $b l a_{\mathrm{KPC}-2}$ in Italy [38] which was comparable to our results where
ST101 isolated were $b l a_{\text {OXA-48 }}$ with four co-producing bla $a_{\mathrm{KPC}-2}$.

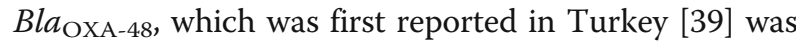
also known to exhibit susceptibility towards extendedspectrum cephalosporins and carbapenems [40] which complicates the detection via routine clinical microbiology laboratory tests. Similarly, K/1310-35 (sensitive to all cephalosporins), K/1310-24 (intermediate to ceftriaxone while being sensitive to all other cephalosporins) and K/ 1311-26 (susceptible dose dependent (SDD) to cefepime while being sensitive to all other cephalosporins) har-

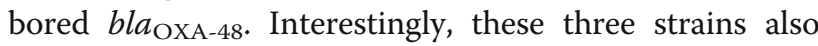
harbored $b l a_{\mathrm{SHV}}$ and $b l a_{\mathrm{CTXM}}$ which was known to hydrolyze cefotaxime and ceftazidime [41] but all three strains were sensitive to both antibiotics in this study.

$B l a_{\mathrm{KPC}}$ is endemic in northeastern regions in USA, Greece and Israel but cross regional spreading into United Kingdom, Brazil, Sweden, India and China had been reported recently [42]. This gene is often detected on mobile genetic elements such as plasmids and transposons which facilitates its rapid dissemination worldwide [37]. Bla $a_{\mathrm{KPC}-2}$ is generally associated with Tn4401 isoforms [43] and in this study, Tn4401b (no deletion in the variable region) was associated with six $b l a_{\mathrm{KPC}-2}$ harboring strains. This isoform had been reported to exhibit lower resistance to carbapenems as compared to other isoforms [28]. However, such conclusions cannot be made in this study as only one isoform type was detected in this study. To the best of our knowledge, this report presented the first identification of $K$. pneumoniae harboring bla $a_{\mathrm{OXA}-48}$ and $b l a_{\mathrm{KPC}-2}$ in Malaysia.

Two strains, K/1304-16 and K/1309-39 demonstrated slight differences in PFGE banding patterns (Dice homology $=84.2 \%)$ despite having the same sequence type, ST147. PFGE is able to detect chromosomal rearrangements [44] which may contribute to differences in their antibiotic and genotypic profiles. K/1309-39 was resistant to imipenem, meropenem and ertapenem $(\mathrm{MIC}=12->32 \mu \mathrm{g} / \mathrm{ml})$ while $\mathrm{K} / 1304-16$ demonstrated low resistance to imipenem, (MIC $=4 \mu \mathrm{g} / \mathrm{ml}$ ) and was sensitive to both meropenem and ertapenem. Furthermore, $b l a_{\mathrm{TEM}}$ carried by both strains was of different gene types. TEM-1 was present in K/1309-39 while TEM-135 was detected in K/1304-16. These two strains can also be distinguished further based on the presence of bla $a_{\mathrm{NDM}-1}$ in K/1309-39 and the presence of inverted repeats (IR) of Tn4401 in K/1304-16.

A majority of NDM cases reported worldwide were related to travel or hospitalization in the Indian subcontinent such as India and Pakistan [45] and ST147 has been shown to be associated with bla $a_{\mathrm{NDM}-1}$ in India [46]. However, in our study, the $b l a_{\mathrm{NDM}-1}$ positive patient had no record of prior travel outside Malaysia. The presence of $b l a_{\mathrm{NDM}}$ without any association with international travel has also been reported by Rimrang and co- 
workers [47] which indicated that the NDM gene was acquired locally.

This study is limited by its small sample size as this study only includes the carbapenem resistant $K$. pneumoniae strains which were isolated during an eight months' period since the first carbapenem resistant $K$. pneumoniae isolation in this hospital. Thus, the findings cannot be generalized to a broader population based on this study alone as it may include potential biases. The significance of mortality rates with imipenem resistance as compared to meropenem and ertapenem resistance cannot be firmly drawn since all the studied strains were imipenem and / or meropenem resistant strains. The increased use of imipenem may have contributed to increased imipenem resistance [48] since five patients were administered with imipenem while only two patients were given meropenem. However, our findings that mechanical ventilation is associated with mortality can be justified as it was also reported in other studies $[25,49]$.

\section{Conclusions}

The emergence of carbapenem resistant $K$ pneumoniae harboring various carbapenemases coupled with the presence of transposon and the loss of porin may contribute to the increasing cases being detected. Thus, microbiological, molecular and clinical data of these strains are important to provide information for a better understanding and to facilitate carbapenem resistance control.

\section{Abbreviations \\ AST: Antimicrobial susceptibility testing; CLSI: Clinical and Laborartory Standards Institute; ESBL: Extended spectrum beta-lactamase; \\ EUCAST: European Committee on Antimicrobial Susceptibility Testing; ICU: Intensive care unit; MHT: Modified Hodge test; MIC: Minimal inhibitory concentration; MLST: Multilocus sequence typing; PFGE: Pulsed-field gel electrophoresis; PTBD: Percutaneous transphetic biliary drainage; \\ RND: Resistance-nodulation-cell division; SDD: Susceptible dose dependent; ST: Sequence type \\ Acknowledgments \\ Not applicable \\ Funding \\ This work was supported by Fundamental Research Grant Scheme (FRGS) from the Ministry of Education, Malaysia (grant number: FP023-2014A), Uni- versity of Malaya Research Grant (UMRG) from University of Malaya (grant number: RP026B-14HTM) and International Society for Infectious Diseases (ISID) research grant (grant number: IF016-2015).}

\section{Availability of data and materials}

All data generated or analyzed during this study are included in this published article.

\section{Authors' contributions}

CSIT and MYMY designed the study. YML and PSXY carried out the experiments and collected the data. CWC performed the statistical analysis. KAJ, SP, RK and RV interpreted the clinical data. YML, KAJ, RK, CWC, SAB and CSJT wrote and revised the manuscript. All authors' read and approved the final version of the manuscript.

\section{Competing interests}

The authors declare that they have no competing interests.
Consent for publication

Not applicable

Ethics approval and consent to participate

Ethics approval (MEC:1059.15) was obtained prior to the start of this study.

\section{Author details}

'Department of Medical Microbiology, University of Malaya, 50603 Kuala Lumpur, Malaysia. ${ }^{2}$ Department of Medicine, University of Malaya, 50603 Kuala Lumpur, Malaysia. ${ }^{3}$ Department of Life Sciences, International Medical University, Bukit Jalil, 57000 Kuala Lumpur, Malaysia. ${ }^{4}$ The Tropical Infectious Diseases Research \& Education Centre (TIDREC), University of Malaya, 50603 Kuala Lumpur, Malaysia.

Received: 12 October 2016 Accepted: 22 December 2016

Published online: 07 January 2017

\section{References}

1. Bratu S, et al. Rapid spread of carbapenem-resistant Klebsiella pneumoniae in New York City: a new threat to our antibiotic armamentarium. Arch Intern Med. 2005;165:1430-5. http://dx.doi.org/10.1001/archinte.165.12.1430.

2. Oteo J, et al. Emergence of CTX-M-15-producing Klebsiella pneumoniae of multilocus sequence types 1, 11, 14, 17, 20, 35 and 36 as pathogens and colonizers in newborns and adults. J Antimicrob Chemother. 2009;64:524-8. http://dx.doi.org/10.1093/jac/dkp211.

3. Macrae $\mathrm{MB}$, et al. A simultaneous outbreak on a neonatal unit of two strains of multiply antibiotic resistant Klebsiella pneumoniae controllable only by ward closure. J Hosp Infect. 2001;49:183-92. http://dx.doi.org/10.1053/jhin. 2001.1066.

4. Paterson DL. Resistance in gram-negative bacteria: Enterobacteriaceae. Am J Med. 2006;119:520-28. http://dx.doi.org/10.1016/j.amjmed.2006.03.013.

5. Yigit $\mathrm{H}$, et al. Novel carbapenem-hydrolyzing beta-lactamase, KPC-1, from a carbapenem-resistant strain of Klebsiella pneumoniae. Antimicrob Agents Chemother. 2001;45:1151-61. http://dx.doi.org/10.1128/AAC.45.4.1151-1161.2001.

6. Nordmann P, Naas T, Poirel L. Global spread of Carbapenemase-producing Enterobacteriaceae. Emerg Infect Dis. 2011;17:1791-8. http://dx.doi.org/10. 3201/eid1710.110655.

7. Queenan AM, Bush K. Carbapenemases: the versatile beta-lactamases. Clin Microbiol Rev. 2007;20:440-58. http://dx.doi.org/10.1128/CMR.00001-07.

8. Palasubramaniam S, Karunakaran R, Gan GG, Muniandy S, Parasakthi N. Imipenem-resistance in Klebsiella pneumoniae in Malaysia due to loss of OmpK36 outer membrane protein coupled with AmpC hyperproduction. Int J Infect Dis. 2007;11:472-4. http://dx.doi.org/10.1016/j.jij. 2007.01.005.

9. Al-Marzooq F, Ngeow YF, Tay ST. Emergence of Klebsiella pneumoniae producing dual carbapenemases (NDM-1 and OXA-232) and 16S rRNA methylase (armA) isolated from a Malaysian patient returning from India. Int J Antimicrob Agents. 2015;45:445-6. http://dx.doi.org/10.1016/j.jjantimicag. 2014.12.013.

10. Ahmad N, et al. Characterization of the first isolate of Klebsiella pneumoniae carrying New Delhi metallo-beta-lactamase and other extended spectrum beta-lactamase genes from Malaysia. J Med Microbiol. 2013;62:804-6. http:// dx.doi.org/10.1099/Jmm.0.050781-0.

11. Hamzan NI, Chan YY, Abdul Rahman R, Hasan H, Abdul Rahman Z. Detection of bla $a_{\mathrm{MP} 4}$ and bla $\mathrm{N}_{\mathrm{NDM}}$ harboring Klebsiella pneumoniae isolates in a university hospital in Malaysia. Emerg Health Threats J. 2015;8:26011. http://dx.doi.org/10.3402/ehtj.v8.26011.

12. Clinical and Laboratory Standards Institute (CLSI). M100-S25: Performance Standards for antimicrobial susceptibility testing. Twenty-fifth international supplement. 2015;35:45-50.

13. The European Committee on Antimicrobial Susceptibility Testing (EUCAST). Breakpoint tables for interpretation of MICs and zone diameters. 2016. Version 6.0, 2016. http://www.eucast.org/clinical_breakpoints/

14. Naas $T$, et al. Genetic structures at the origin of acquisition of the beta-

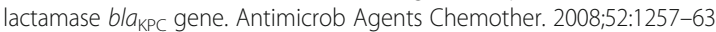
http://dx.doi.org/10.1128/AAC.01451-07.

15. Poirel L, Héritier C, Tolün V, Nordmann P. Emergence of oxacillinasemediated resistance to imipenem in Klebsiella pneumoniae. Antimicrob Agents Chemother. 2004;48:15-22. http://dx.doi.org/10.1128/AAC.48.1.15-22. 2004.

16. Yan JJ, et al. Metallo-beta-lactamases in clinical Pseudomonas isolates in Taiwan and identification of VIM-3, a novel variant of the VIM-2 enzyme. 
Antimicrob Agents Chemother. 2001;45:2224-8. http://dx.doi.org/10.1128/ AAC.45.8.2224-2228.2001.

17. Castanheira M, Toleman MA, Jones RN, Schmidt FJ, Walsh T. Molecular characterization of a beta-lactamase gene, bla $a_{\mathrm{GI} M-1}$, encoding a new subclass of metallo-beta-lactamase. Antimicrob Agents Chemother. 2004;48: 4654-61. http://dx.doi.org/10.1128/AAC.48.12.4654-4661.2004.

18. Dallenne C, Da Costa A, Decré D, Favier C, Arlet G. Development of a set of multiplex PCR assays for the detection of genes encoding important betalactamases in Enterobacteriaceae. J Antimicrob Chemother. 2010;65:490-5. http://dx.doi.org/10.1093/jac/dkp498.

19. Mulvey MR, Grant JM, Plewes K, Roscoe D, Boyd DA. New Delhi metallobeta-lactamase in Klebsiella pneumoniae and Escherichia coli. Canada Emerg Infect Dis. 2011;17:103-6. http://dx.doi.org/10.3201/eid1701.101358.

20. Eckert C, et al. Dissemination of CTX-M-type beta-lactamases among clinical isolates of Enterobacteriaceae in Paris. France Antimicrob Agents Chemother. 2004;48:1249-55. http://dx.doi.org/10.1128/AAC.48.4.1249-1255. 2004.

21. Kaczmarek FM, Dib-Hajj F, Shang W, Gootz TD. High-level carbapenem resistance in a Klebsiella pneumoniae clinical isolate is due to the combination of bla $a_{\text {ACT-1 }} \beta$-lactamase production, porin OmpK35/36 insertional inactivation, and down-regulation of the phosphate transport porin phoE. Antimicrob Agents Chemother. 2006;50:3396-406. http://dx.doi. org/10.1128/AAC.00285-06

22. Cuzon $\mathrm{G}$, et al. Worldwide diversity of Klebsiella pneumoniae that produce beta-lactamase bla kPC-2 gene. Emerg Infect Dis. 2010;16:1349-56. http://dx. doi.org/10.3201/eid1609.091389.

23. Haller S, et al. What caused the outbreak of ESBL-producing Klebsiella pneumoniae in a neonatal intensive care unit, Germany 2009 to 2012? Reconstructing transmission with epidemiological analysis and wholegenome sequencing. BMJ Open. 2015;5:e007397. http://dx.doi.org/10.1136/ bmjopen-2014-007397.

24. Dautzenberg MJD, et al. The Association Between Colonization With Carbapenemase-Producing Enterobacteriaceae and Overall ICU Mortality: An Observational Cohort Study. Crit Care Med. 2015;43:1170-7. http://dx.doi. org/10.1097/Ccm.0000000000001028.

25. Saidel-Odes $L$, Borer A. Limiting and controlling carbapenem-resistant Klebsiella pneumoniae. Infect Drug Resist. 2013;7:9-14. http://dx.doi.org/10. 2147/IDR.S44358.

26. Patel $\mathrm{N}$, et al. Clinical epidemiology of carbapenem-intermediate or -resistant Enterobacteriaceae. J Antimicrob Chemother. 2011;66:1600-8. http://dx.doi.org/10.1093/jac/dkr156.

27. Crowley B, Benedi VJ, Domenech-Sanchez A. Expression of SHV-2 betalactamase and of reduced amounts of OmpK36 porin in Klebsiella pneumoniae results in increased resistance to cephalosporins and carbapenems. Antimicrob Agents Chemother. 2002;46:3679-82. http://dx. doi.org/10.1128/Aac.46.11.3679-3682.2002.

28. Kitchel B, et al. Genetic factors associated with elevated carbapenem resistance in KPC-producing Klebsiella pneumoniae. Antimicrob Agents Chemother. 2010;54:4201-7. http://dx.doi.org/10.1128/AAC.00008-10.

29. Harino T, et al. Meropenem resistance in imipenem-susceptible meropenem-resistant Klebsiella pneumoniae isolates not detected by rapid automated testing systems. J Clin Microbiol. 2013;51(8):2735-8. http://dx.doi. org/10.1128/JCM.02649-12.

30. Shigemoto $\mathrm{N}$, et al. Emergence in Japan of an imipenem-susceptible, meropenem-resistant Klebsiella pneumoniae carrying blalMP-6. Diagn Microbiol Infect Dis. 2012;72(1):109-12. http://dx.doi.org/10.1016/j. diagmicrobio.2011.09.019.

31. Pai $\mathrm{H}$, et al. Carbapenem resistance mechanisms in Pseudomonas aeruginosa clinical isolates. Antimicrob Agents Chemother. 2001;45(2):480-4. http://dx. doi.org/10.1128/AAC.45.2.480-484.2001.

32. Epp SF, et al. C-terminal region of Pseudomonas aeruginosa outer membrane porin OprD modulates susceptibility to meropenem. Antimicrob Agents Chemother. 2001;45(6):1780-7. http://dx.doi.org/10.1128/AAC.45.6.1780-1787.2001.

33. Kao CY, et al. Overproduction of active efflux pump and variations of OprD dominate in imipenem-resistant Pseudomonas aeruginosa isolated from patients with bloodstream infections in Taiwan. BMC Microbiol. 2016;16(1): 107. http://dx.doi.org/10.1186/s12866-016-0719-2.

34. Kitchel B, et al. Molecular Epidemiology of KPC-Producing Klebsiella pneumoniae Isolates in the United States: Clonal Expansion of Multilocus Sequence Type 258. Antimicrob Agents Chemother. 2009;53:3365-70. http://dx.doi.org/10.1128/Aac.00126-09.
35. Snitkin E, et al. Tracking a hospital outbreak of carbapenem-resistant klebsiella pneumoniae with whole-genome sequencing. Sci Transl Med. 2012;4(148):14ra116. http://dx.doi.org/10.1126/scitranslmed.3004129.

36. Potron A, Poirel L, Rondinaud E, Nordmann P. Intercontinental spread of OXA-48 beta-lactamase-producing Enterobacteriaceae over a 11-year period, 2001 to 2011. Euro Surveill. 2013:18. http://dx.doi.org/10.2807/15607917.ES2013.18.31.20549.

37. Nordmann P, Cuzon G, Naas T. The real threat of Klebsiella pneumoniae carbapenemase-producing bacteria. Lancet Infect Dis. 2009;9:228-36. http:// dx.doi.org/10.1016/S1473-3099(09)70054-4.

38. Mammina C, et al. Sequence type 101 (ST101) as the predominant carbapenem-non-susceptible Klebsiella pneumoniae clone in an acute general hospital in Italy. Int J Antimicrob Agents. 2012;39:543-5. http://dx. doi.org/10.1016/j.jijantimicag.2012.02.012.

39. Pfeifer $Y$, et al. Emergence of OXA-48-type carbapenemase-producing Enterobacteriaceae in German hospitals. Antimicrob Agents Chemother. 2012;56:2125-8. http://dx.doi.org/10.1128/AAC.05315-11.

40. Poirel L, Potron A, Nordmann P. OXA-48-like carbapenemases: the phantom menace. J Antimicrob Chemother. 2012;67:1597-606. http://dx.doi.org/10. 1093/jac/dks121

41. Bradford PA. Extended-spectrum beta-lactamases in the 21st century: Characterization, epidemiology, and detection of this important resistance threat. Clin Microbiol Rev. 2001;14:933-51. http://dx.doi.org/10.1128/Cmr.14. 4.933-951.2001.

42. Arnold RS, et al. Emergence of Klebsiella pneumoniae carbapenemaseproducing bacteria. South Med J. 2011;104:40-5. http://dx.doi.org/10.1097/ SMJ.0b013e3181fd7d5a.

43. Gootz TD, et al. Genetic organization of transposase regions surrounding blakPC carbapenemase genes on plasmids from Klebsiella strains isolated in a New York City hospital. Antimicrob Agents Chemother. 2009;53:1998-2004. http://dx.doi.org/10.1128/AAC.01355-08.

44. Vimont S, Mnif B, Fevre C, Brisse S. Comparison of PFGE and multilocus sequence typing for analysis of Klebsiella pneumoniae isolates. J Med Microbiol. 2008;57:1308-10. http://dx.doi.org/10.1099/jmm.0.2008/003798-0.

45. Johnson AP, Woodford N. Global spread of antibiotic resistance: the example of New Delhi metallo-beta-lactamase (NDM)-mediated carbapenem resistance. J Med Microbiol. 2013;62:499-513. http://dx.doi.org/ 10.1099/jmm.0.052555-0.

46. Lascols C, Peirano G, Hackel M, Laupland KB, Pitout JDD. Surveillance and molecular epidemiology of Klebsiella pneumoniae isolates that produce carbapenemases: first report of OXA-48-like enzymes in North America. Antimicrob Agents Chemother. 2013;57:130-6. http://dx.doi.org/10.1128/ AAC.01686-12.

47. Rimrang B, et al. Emergence of NDM-1-and IMP-14a-producing Enterobacteriaceae in Thailand. J Antimicrob Chemother. 2012;67:2626-30. http://dx.doi.org/10.1093/jac/dks267.

48. McLaughlin M, et al. Correlations of antibiotic use and carbapenem resistance in enterobacteriaceae. Antimicrob Agents Chemother. 2013; 57(10):5131-3. http://dx.doi.org/10.1128/AAC.00607-13.

49. Schwaber MJ, et al. Predictors of carbapenem-resistant Klebsiella pneumoniae acquisition among hospitalized adults and effect of acquisition on mortality. Antimicrob Agents Chemother. 2008;52:1028-33. http://dx.doi. org/10.1128/AAC.01020-07.

\section{Submit your next manuscript to BioMed Central and we will help you at every step:}

- We accept pre-submission inquiries

- Our selector tool helps you to find the most relevant journal

- We provide round the clock customer support

- Convenient online submission

- Thorough peer review

- Inclusion in PubMed and all major indexing services

- Maximum visibility for your research

Submit your manuscript at www.biomedcentral.com/submit
C Biomed Central 